\title{
Optimization of Canalicular ABC Transporter Function in HuH-7 Cells by Modification of Culture Conditions ${ }^{[]}$
}

\author{
(1) Hee Eun Kang, Melina M. Malinen, Chitra Saran, (Paavo Honkakoski, and $\odot$ Kim L.R. Brouwer
}

College of Pharmacy and Integrated Research Institute of Pharmaceutical Sciences, The Catholic University of Korea, Bucheon, South Korea (H.E.K.); Division of Pharmacotherapy and Experimental Therapeutics, UNC Eshelman School of Pharmacy (H.E.K., M.M.M., C.S., P.H., K.L.R.B.) and Department of Pharmacology, UNC School of Medicine (C.S.), University of North Carolina at Chapel Hill, Chapel Hill, North Carolina; and School of Pharmacy, University of Eastern Finland, Kuopio, Finland (M.M.M., P.H.)

Received April 24, 2019; accepted July 19, 2019

\begin{abstract}
Human hepatoma cell lines are useful for evaluation of drug-induced hepatotoxicity, hepatic drug disposition, and drug-drug interactions. However, their applicability is compromised by aberrant expression of hepatobiliary transporters. This study was designed to evaluate whether extracellular matrix (Matrigel) overlay and dexamethasone (DEX) treatment would support cellular maturation of long-term HuH-7 hepatoma cell cultures and improve the expression, localization, and activity of canalicular ATP-binding cassette (ABC) transporters, multidrug resistance protein 1 (MDR1/P-glycoprotein/ABCB1), multidrug resistance-associated protein 2 (MRP2/ ABCC2), and bile salt export pump (BSEP/ABCB11). Matrigel overlay promoted the maturation of $\mathrm{HuH}-7$ cells toward cuboidal, hepatocyte-like cells displaying bile canaliculi-like structures visualized by staining for filamentous actin (F-actin), colocalization of MRP2 with F-actin, and by accumulation of the MRP2 substrate 5(6)-carboxy-2', $7^{\prime}$-dichlorofluorescein (CDF) within the tubular canaliculi. The cellular phenotype was rather homogenous in the Matrigel-overlaid cultures, whereas the standard $\mathrm{HuH}-7$ cultures contained both hepatocyte-like cells and flat epithelium-like cells. Only
\end{abstract}

Matrigel-overlaid HuH-7 cells expressed MDR1 at the canaliculi and excreted the MDR1 probe substrate digoxin into biliary compartments. DEX treatment resulted in more elongated and branched canaliculi and restored canalicular expression and function of BSEP. These findings suggest that hepatocyte polarity, elongated canalicular structures, and proper localization and function of canalicular $A B C$ transporters can be recovered, at least in part, in human hepatoma HuH-7 cells by applying the modified culture conditions.

\section{SIGNIFICANCE STATEMENT}

We report the first demonstration that proper localization and function of canalicular $A B C$ transporters can be recovered in human hepatoma HuH-7 cells by modification of cell culture conditions. Matrigel overlay and dexamethasone supplementation increased the proportion of hepatocyte-like cells, strongly augmented the canalicular structures between the cells, and restored the localization and function of key canalicular ABC transporters. These results will facilitate the development of reproducible, economical, and easily achievable liver cell models for drug development.
This work was supported by the National Institutes of Health National Institute of General Medical Sciences under Award Numbers R01 GM041935 and R35 GM122576 to Prof. K.L.R.B. Prof. H.E.K. was supported, in part, by a National Research Foundation of Korea grant funded by the Korean government (MSIT) (No. 2019R1F1A1052243) and by the Catholic University of Korea, Research Fund, 2018. Dr. M.M.M. was supported, in part, by the Finnish Cultural Foundation and Orion Research Foundation. Prof. P.H. was supported in part by the ERASMUS+Global exchange program and the University of Eastern Finland. Disclosure: Dr. K.L.R.B. is a coinventor of the sandwich-cultured hepatocyte technology for quantification of biliary excretion (B-CLEAR) and related technologies, which have been licensed exclusively to Qualyst Transporter Solutions, recently acquired by BiolVT.

https://doi.org/10.1124/dmd.119.087676.

S This article has supplemental material available at dmd.aspetjournals.org.

\section{Introduction}

In vitro human hepatic cell line models are widely used for evaluating hepatic drug disposition, drug-drug interactions, and drug-induced hepatotoxicity in drug development. Characteristics, applications, and limitations of human hepatoma cell lines commonly used in drug metabolism and hepatotoxicity studies have been reviewed (Donato et al., 2013). For example, the human hepatocellular carcinoma cell line HepG2 displays many differentiated hepatic functions and abundant phase II enzymes but has poor expression of cytochrome P450s (CYPs) and limited responsiveness to CYP inducers. HepaRG cells are more suitable for drug metabolism and CYP induction studies, and they express several functional drug-metabolizing enzymes (DMEs) and transporters (Le Vee et al., 2013). However, HepaRG cells are a mixed population of hepatocyte-like and cholangiocyte-like cells and do not differ from HepG2 cells in their sensitivity to and detection of hepatotoxic drugs (Gripon et al., 2002; Gerets et al., 2012). Although these cell lines

ABBREVIATIONS: ABC, ATP-binding cassette; BEI, biliary excretion index; BSEP, bile salt export pump; CDF, 5(6)-carboxy-2',7'dichlorofluorescein; CDFDA, CDF diacetate; CYP, cytochrome P450; DAPI, 4',6-diamidino-2-phenylindole; DEX, dexamethasone; DME, drugmetabolizing enzyme; DMSO, dimethyl sulfoxide; EGTA, ethylene glycol-bis( $\beta$-aminoethyl ether)- $N, N, N^{\prime}, N^{\prime}$-tetraacetic acid, egtazic acid; F-actin, filamentous actin; FBS, fetal bovine serum; HBSS, Hanks' balanced salt solution; LC-MS/MS, liquid chromatography-tandem mass spectrometry; MDR1, multidrug resistance protein 1; MRP, multidrug resistance-associated protein; NTCP, sodium taurocholate cotransporting polypeptide; OATP, organic anion transporting polypeptide; OST $\alpha / \beta$, organic solute transporter $\alpha / \beta$; PBS, phosphate buffered saline. 
are economical, reproducible, and easy to maintain compared with primary human hepatocytes, several key hepatocyte functions are compromised (Olsavsky et al., 2007; Guo et al., 2011; Sison-Young et al., 2015).

The HuH-7 hepatoma cell line (Nakabayashi et al., 1982) displays expression patterns of DME and transporter mRNAs that are more similar to primary human hepatocytes than those of widely used HepG2 cells (Guo et al., 2011). Moreover, recent studies on transporter protein expression revealed that hepatobiliary transporters such as multidrug resistance protein 1 (MDR1/P-glycoprotein/ABCB1), multidrug resistance-associated protein 2 (MRP2/ABCC2), organic anion-transporting polypeptide (OATP) 1B1 [solute carrier organic anion transporter (SLCO)1B1], and OATP2B1 (SLCO2B1) are present in HuH-7 cultures, albeit at lower levels of expression and function than in primary human hepatocytes (Jouan et al., 2017; Shi et al., 2018; Malinen et al., 2019). The expression of major bile acid transporters, sodium taurocholate cotransporting polypeptide (NTCP/SLC10A1), and bile salt export pump (BSEP/ABCB11) was at low or negligible levels in standard HuH-7 cultures, whereas the alternative bile acid transporters, organic solute transporter $\alpha / \beta(\mathrm{OST} \alpha / \beta / \mathrm{SLC} 51 \mathrm{~A} / \mathrm{B})$ and MRP4 (ABCC4) were expressed at higher levels in $\mathrm{HuH}-7$ cells than in human hepatocytes (Malinen et al., 2019). Importantly, molecular mechanisms for transcriptional regulation such as farnesoid $\mathrm{X}$ receptor-mediated BSEP induction and nuclear factor erythroid 2-related factor 2-mediated induction of MRP2 and breast cancer resistance protein (BCRP/ABCG2) are retained in HuH-7 cells (Jouan et al., 2017).

Interestingly, maintaining confluent $\mathrm{HuH}-7$ cultures for several weeks induced the mRNA expression of multiple DMEs and transporters, including CYP3A4, BSEP, MDR1, and OATP1B1, and their regulators, such as constitutive androstane receptor, pregnane $\mathrm{X}$ receptor, retinoid $\mathrm{X}$ receptor, and hepatocyte nuclear factor- $4 \alpha$ (Sivertsson et al., 2010). Recently, our group demonstrated that the extended culture time induced the protein expression of solute carrier (SLC) transporters OST $\alpha / \beta$ and OATP1B3 (Malinen et al., 2019). Some HuH-7 cells in our long-term cultures displayed a cuboidal, hepatocyte-like morphology with bile canaliculi-like structures. This phenotype resembled that of differentiated HepaRG (Gripon et al., 2002; Hoekstra et al., 2011) and primary human hepatocyte cultures (Hoffmaster et al., 2004).

Because extension of the culture time alone did not restore expression of all key bile acid transporters in HuH-7 cells (Sivertsson et al., 2010; Malinen et al., 2019), supplementation of these cultures with known inducers of hepatic differentiation and the use of extracellular matrices might be beneficial. Primary human hepatocyte or HepaRG cultures are usually supplemented with insulin and glucocorticoids such as DEX. Insulin improves survival and attachment of hepatocytes and enhances amino acid transport, protein synthesis, glycogenesis, and lipogenesis (Tanaka et al., 1978; Varandani et al., 1982). DEX promotes arrangement of the cellular cytoskeleton, gap junctions, formation of bile canaliculi-like networks, as well as CYP activities in sandwich-cultured hepatocytes (Swift et al., 2010). The full differentiation of HepaRG cell cultures also requires dimethyl sulfoxide (DMSO) (Gripon et al., 2002). However, DMSO is not necessary for maturation of HuH-7 cells, because long-term cultures with and without DMSO have shown comparable DME gene expression profiles (Sivertsson et al., 2010). Incorporation of extracellular matrices such as Matrigel, which is a laminin- and collagen-rich basement membrane matrix, in primary hepatocyte and HepaRG cultures has further improved the maintenance of liver-specific functions and cell polarity (LeCluyse et al., 1994; Swift et al., 2010; Jackson et al., 2016). Matrigel overlay restored hepatocyte-like morphology, elevated metabolic competence, improved responsiveness to DME inducers, and increased function of hepatic uptake transporters.
To the best of our knowledge, there are no reports on the effect of extracellular matrix or supplements other than DMSO on drug and bile acid transporters in HuH-7 cells. Therefore, the aim of the present study was to evaluate whether the addition of an extracellular matrix overlay and/or DEX supplementation, together with the extended culture time, could improve the expression, localization, and activity of the canalicular ATP-binding cassette (ABC) transporters in HuH-7 cells. To this end, we performed immunocytochemical staining and immunoblotting of MDR1, MRP2, and BSEP transporters. In addition, transport studies were performed with the probe substrates 5(6)-carboxy-2',7'-dichlorofluorescein (CDF), digoxin, pravastatin, and $\left[{ }^{3} \mathrm{H}\right]$-taurocholate (TCA).

\section{Materials and Methods}

Cell Culture. The human hepatoma HuH-7 cell line (JCRB0403) was obtained from Sekisui Xenotech (Kansas City, KS). The cells were cultured in T75 flasks with a tissue culture-treated surface (83.3911.002; Sarstedt, Newton, $\mathrm{NC}$ ) at $37^{\circ} \mathrm{C}$ in a $5 \% \mathrm{CO}_{2}$ atmosphere in maintenance medium [high glucose Dulbecco's modified Eagle's medium (Gibco 11995-065; Thermo Fisher Scientific, Waltham, MA) supplemented with $10 \%$ fetal bovine serum (FBS), $100 \mathrm{IU} / \mathrm{ml}$ penicillin, and $100 \mu \mathrm{g} / \mathrm{ml}$ streptomycin]. The identity of the $\mathrm{HuH}-7$ cell line was verified by amplification of 17 short tandem repeats by the Cell Line Authentication Service of the American Type Culture Collection (ATCC, Manassas, VA). For long-term confluent culture, the cells were seeded on 24-well plates with a tissue culture-treated surface (353226; Thermo Fisher Scientific) $\left(9 \times 10^{4}\right.$ cells/well) and the cultures reached confluence within a few days. The cultures were maintained for 4 weeks, and the medium was renewed every 2-3 days. One week after plating the cells, the maintenance medium was supplemented with $0,0.1$, or $1 \mu \mathrm{M}$ DEX. These concentrations were selected on the basis of reported DEX concentrations that maintain the expression of BSEP (Warskulat et al., 1999) and MRP2 (Kubitz et al., 1999) in primary rat hepatocyte cultures. Similar concentrations are also widely used for primary human hepatocyte cultures. Three weeks after seeding, the cultures were further supplemented with Matrigel overlay (Matrigel, 354234 [Lot 6291006 and Lot 7016291]; Corning, Bedford, MA) at a concentration of $0.25 \mathrm{mg} / \mathrm{ml}$ in ice-cold maintenance medium supplemented with $0,0.1$, or $1 \mu \mathrm{M}$ DEX. The expression and function of transporters were assessed after 4 weeks of culture (4-week confluent cells).

Immunofluorescence Microscopy. Four-week confluent HuH-7 cells, cultured on glass-bottom 24-well plates (MatTek Corporation, Ashland, MA), were fixed in $4 \%$ paraformaldehyde for 15 minutes at room temperature. After permeabilization with $0.1 \%$ Triton $\mathrm{X}-100$ in phosphate-buffered saline (PBS) for 15 minutes, the samples were blocked with $10 \%$ FBS, $0.2 \%$ bovine serum albumin (BSA), and $0.1 \%$ Triton X-100 in PBS for 1 hour. The cells were next incubated with primary antibodies [anti-MDR1 (1:50 dilution; Santa Cruz Biotechnology, Dallas, TX), anti-MRP2 (1:20 dilution; Kamiya Biochemical Company, Seattle, WA), or anti-BSEP (1:100 dilution; Abcam, Cambridge, MA)] in $5 \%$ FBS and $0.2 \%$ BSA in PBS overnight at $4^{\circ} \mathrm{C}$. This was followed by incubation with Alexa Fluor 488-labeled goat anti-mouse or goat anti-rabbit secondary antibody (Thermo Fisher Scientific) for 1 hour at room temperature. Nuclei and filamentous actin (F-actin) were visualized by 4,6-diamidino-2phenylindole (DAPI) and Alexa Fluor 594-labeled phalloidin (Thermo Fisher Scientific). The samples were mounted with ProLong Gold antifade reagent, and the expression and localization of each transporter was examined using a LSM 710 confocal microscope (Zeiss, Oberkochen, Germany). Image files were processed with ImageJ. The length of phalloidin-stained F-actin-rich tubules (i.e., bile canaliculi) was measured in the representative field view images from three different wells for each condition.

Western Blot Analysis. Membrane proteins of HuH-7 cells and cryopreserved human hepatocytes (Lot HUP1001, 10-donor pool; Lonza BioResearch, Durham, NC) were extracted using ProteoExtract Native Membrane Protein Extraction kit (Calbiochem; EMD Biosciences, Inc., Darmstadt, Germany) according to the manufacturer's instructions. Protein concentration was determined using Pierce BCA protein assay kit (Thermo Fisher Scientific). Fifteen micrograms of membrane proteins were mixed with NuPAGE LDS sample buffer (Thermo Fisher Scientific) and subjected to SDS-PAGE using NuPAGE 7\% Tris-Acetate or $4 \%-12 \%$ Bis-Tris gels. The proteins were then transferred to a polyvinylidene 
difluoride membrane (GE Healthcare, Little Chalfont, Buckinghamshire, UK). After blocking in Tris-buffered saline ( $250 \mathrm{mM}$ Tris-HCl, pH 7.4, $200 \mathrm{mM} \mathrm{NaCl})$ containing $0.1 \%(\mathrm{v} / \mathrm{v})$ Tween 20 and $5 \%(\mathrm{w} / \mathrm{v})$ fat-free milk powder, the membranes were incubated with each primary antibody [mouse anti-MDR1 (1:250 dilution; Covance Research, Princeton, NJ), mouse anti-MRP2 (1:100 dilution; Kamiya Biochemical Company), rabbit anti-BSEP antibody (1:500 dilution; Abcam), or rabbit anti- $\mathrm{Na}^{+} / \mathrm{K}^{+}$ATPase (1:200 dilution; Santa Cruz Biotechnology)] followed by incubation with anti-mouse (1:10,000 dilution) or anti-rabbit (1:5000 dilution) horseradish peroxidase-conjugated secondary antibodies (Santa Cruz Biotechnology). Signals were detected using ECL Select Western Blotting Detection Reagent (GE Healthcare) and Molecular Imager VersaDoc imaging system (Bio-Rad, Hercules, CA). Signal intensities of the transporters were normalized to the corresponding $\mathrm{Na}^{+} / \mathrm{K}^{+}$ATPase signals.

Analysis of Functional Polarity. Formation of functional bile canaliculi in HuH-7 cells was characterized using CDF diacetate (CDFDA), which is hydrolyzed by intracellular esterases to $\mathrm{CDF}$. $\mathrm{CDF}$ is transported into the bile canaliculi by MRP2 (Zamek-Gliszczynski et al., 2003). The protocol was adapted from B-CLEAR (BioIVT, Durham, NC) technology (Liu et al., 1999; Swift et al., 2010). Briefly, the cells were preincubated in either standard or $\mathrm{Ca}^{2+}$-free $\left(\mathrm{Ca}^{2+} / \mathrm{Mg}^{2+}\right.$-free buffer containing $1 \mathrm{mM}$ EGTA) Hanks' balanced salt solution (HBSS) for 25 minutes prior to incubation with $2 \mu \mathrm{M}$ CDFDA in standard HBSS for 20 minutes at $37^{\circ} \mathrm{C}$. Before imaging, the cells were washed with standard HBSS.

A
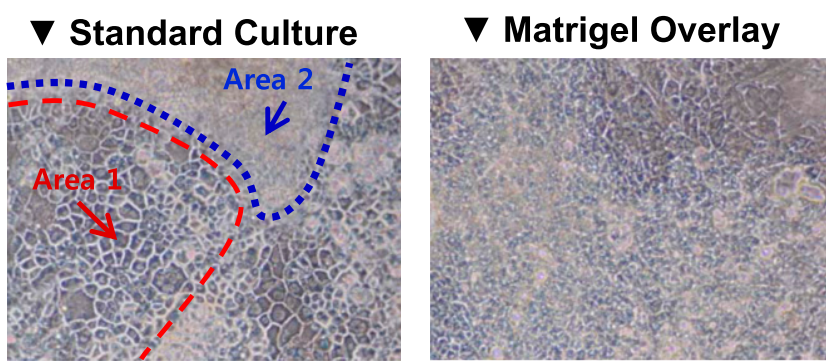

B
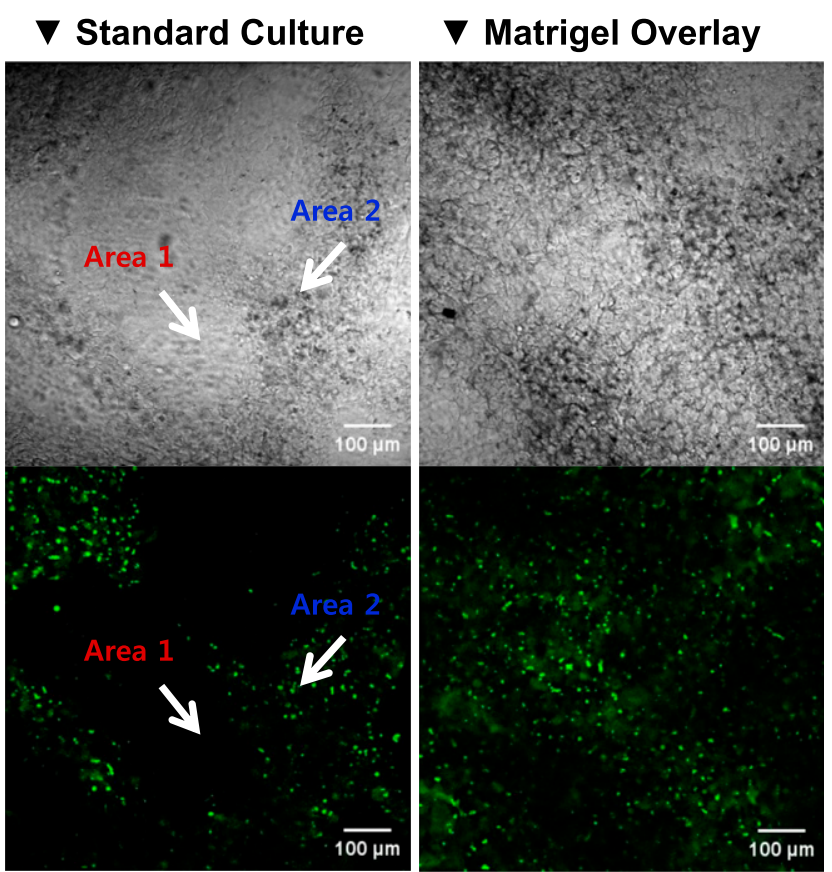

Fig. 1. Representative cellular morphology and bile canaliculi-like structures in 4week HuH-7 cultures. (A) Phase-contrast microscopy image of 4-week confluent HuH-7 cells cultured without (standard) and with Matrigel overlay. (B) Localization of the fluorescent canalicular marker CDF, the metabolite of CDFDA, in 4-week standard and Matrigel-overlaid $\mathrm{HuH}-7$ cultures.
The fluorescence of CDF was observed by using LSM 710 confocal laser scanning microscopy with an excitation wavelength of $488 \mathrm{~nm}$, or a Cytation 3 Cell imaging multi-mode reader with excitation and emission wavelengths of 469 and $525 \mathrm{~nm}$, respectively (Biotek, Winooski, VT). Image files were processed with ImageJ.

Quantitation of Biliary Excretion by Canalicular ABC Transporters. To evaluate functional activity of the canalicular ABC transporters in $\mathrm{HuH}-7$ cells, accumulation of probe substrates (digoxin for MDR1 (Bi et al., 2006), pravastatin for MRP2 (Matsushima et al., 2005), and [ $\left.{ }^{3} \mathrm{H}\right]$-taurocholate (TCA; PerkinElmer Inc., Boston, MA) for BSEP (Bi et al., 2006; Yang et al., 2015]) was investigated by applying B-CLEAR technology (BioIVT). First, the cells were preincubated for 25 minutes (digoxin-pravastatin assay) or 10 minutes $\left(\left[{ }^{3} \mathrm{H}\right]\right.$-TCA assay) in standard or $\mathrm{Ca}^{2+}$-free HBSS (Swift et al., 2010). Cells were treated then with a combination of $2 \mu \mathrm{M}$ digoxin and $2 \mu \mathrm{M}$ pravastatin in standard HBSS for 15 minutes, or with $2 \mu \mathrm{M}\left[{ }^{3} \mathrm{H}\right]-\mathrm{TCA}(200 \mathrm{nCi} / \mathrm{ml})$ in standard HBSS for 10 minutes. At the end of incubation, the cells were washed three times with icecold standard HBSS followed by cell lysis. For the digoxin-pravastatin assay, the

\section{A Length of bile canaliculi-like structures in $\mathrm{HuH}-7$ cells}

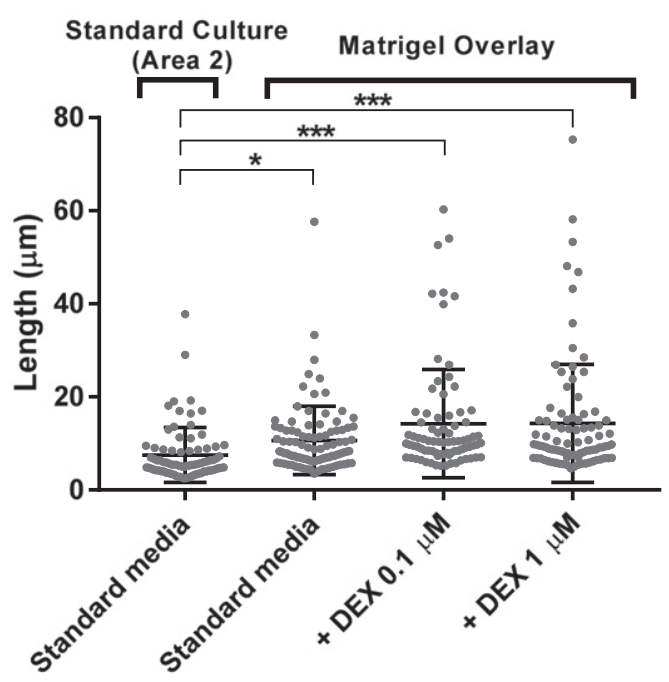

B Mean number of bile canaliculi-like structures per cell

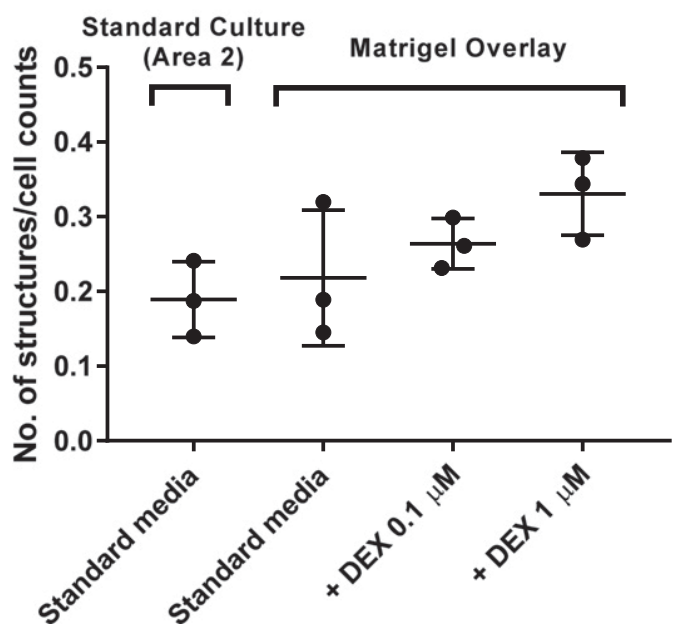

Fig. 2. Effect of Matrigel overlay and DEX on the length and number of bile canaliculi-like structures in confluent 4-week HuH-7 cultures. The (A) length $($ mean \pm S.D.) and $(B)$ number (mean \pm S.D.) of phalloidin-stained F-actin-rich tubules (i.e., bile canaliculi) normalized by cell count on the basis of DAPI-labeled nuclei are shown. Each representative field view $(212.55 \times 212.55 \mu \mathrm{m})$ from three different wells per each condition was used for the measurement. $* P<0.05$; *** $P<0.001$ (one-way ANOVA with Games-Howell test). 
cells were lysed with $0.2 \mathrm{ml}$ of internal standard solution containing $250 \mathrm{ng} / \mathrm{ml}$ digoxin-d 3 and $100 \mathrm{ng} / \mathrm{ml}$ pravastatin-d 3 in methanol and $0.1 \mathrm{ml}$ of distilled water. For the $\left[{ }^{3} \mathrm{H}\right]$-TCA assay, the cells were solubilized in $0.4 \mathrm{ml}$ of $0.5 \%$ Triton X-100 and $0.005 \%$ Antifoam-A in PBS, and radioactivity of the cell lysates was quantified using Bio-safe II counting cocktail (Research Products International Corp., Mt Prospect, IL) and a Tri-carb 3100TR liquid scintillation analyzer (PerkinElmer Inc.).

Accumulation of substrate(s) in cells and bile canaliculi-like structures (i.e., "Cells + Bile," preincubation with standard HBSS) or only in the cells (i.e., "Cells," preincubation with $\mathrm{Ca}^{2+}$-free HBSS) was determined in triplicate in two or three independent studies. The biliary excretion index (BEI), which represents the fraction of the accumulated substrate that resides in the bile canaliculi, the apparent in vitro uptake clearance $\left(\mathrm{CL}_{\text {uptake,app }}\right)$, and the biliary clearance $\left(\mathrm{CL}_{\text {biliary,app }}\right)$ values were calculated using the following equations (Liu et al., 1999; Bi et al., 2006; Swift et al., 2010):

$$
\begin{aligned}
& \text { BEI }(\%)=\left[\left(\text { Accumulation }_{\text {Cells }}+\text { Bile }- \text { Accumulation }_{\text {Cells }}\right) /\right. \\
& \text { Accumulation } \left._{\text {Cells }}+\text { Bile }\right] \times 100
\end{aligned}
$$

$\mathrm{CL}_{\text {uptake,app }}=\left(\right.$ Accumulation $_{\text {Cells }}+$ Bile $) /\left(\right.$ Incubation Time $\times$ Concentration $\left._{\text {media }}\right)$

$$
\begin{aligned}
& \mathrm{CL}_{\text {biliary,app }}=\left(\text { Accumulation }_{\text {Cells }}+\text { Bile }- \text { Accumulation }_{\text {Cells }}\right) / \\
& \text { (Incubation Time } \times \text { Concentration }_{\text {media }} \text { ) }
\end{aligned}
$$

LC-MS/MS Analysis of Digoxin and Pravastatin. Concentrations of digoxin and pravastatin in the cell lysates were analyzed by liquid chromatography-tandem mass spectrometry (LC-MS/MS) analysis using a Thermo Finnigan TSQ Quantum Ultra tandem mass spectrometer equipped with a heated electrospray ionization source (San Jose, CA) and Accela LC system (Thermo Fisher Scientific). Instrument control, data acquisition, and processing were performed using Xcalibur software (Thermo Fisher Scientific). After centrifugation at 12,000g for 5 minutes, cell lysate samples (10 $\mu$ l of supernatant) were injected directly onto a reverse-phase HPLC column (Aquasil $\mathrm{C}_{18} ; 2.1 \mathrm{~mm}$ i.d. $\times 50 \mathrm{~mm}$ 1; particle size, $3 \mu \mathrm{m}$; Thermo Fisher Scientific). The gradient elution of the mobile phase consisted of buffers A (10 mM ammonium formate in water) and $\mathrm{B}(10 \mathrm{mM}$ ammonium formate in methanol) run at a constant flow rate of $0.3 \mathrm{ml} / \mathrm{min}$ : $0-1.5$ minutes, $5 \%-80 \% \mathrm{~B} ; 1.5-3.5$ minutes, $80 \% \mathrm{~B} ; 3.5-3.6$ minutes, $80 \%-5 \% \mathrm{~B} ; 3.6-7$ minutes, $5 \% \mathrm{~B}(\mathrm{v} / \mathrm{v})$. The column temperature was maintained at $25^{\circ} \mathrm{C}$ and that of the autosampler at $15^{\circ} \mathrm{C}$. Analyses of digoxin and pravastatin were carried out in negative ion mode with the spray voltage set at $3 \mathrm{kV}$. Both heated vapor and capillary temperatures were set at $350^{\circ} \mathrm{C}$. Nitrogen sheath and auxiliary gases were set at 30 and 5 psi, respectively. The

\section{A Standard Culture (Area 1)}

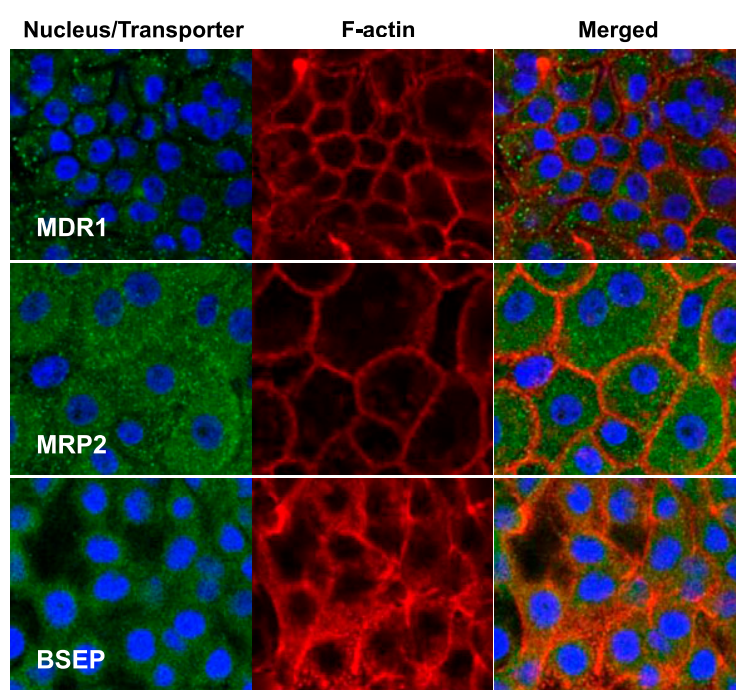

selected collision energy and precursor $\left([\mathrm{M}-\mathrm{H}]^{-}\right)$to product ion transitions were as follow: digoxin $(35 \mathrm{eV}, \mathrm{m} / \mathrm{z} 779.3 \rightarrow 649.3)$; digoxin-d3 $(34 \mathrm{eV}, \mathrm{m} / \mathrm{z}, 782.3 \rightarrow 652.3)$; pravastatin $(16 \mathrm{eV}, \mathrm{m} / z \quad 423.2 \rightarrow 321.2)$; and pravastatin-d3 $(18 \mathrm{eV}, \mathrm{m} / z$ $426.2 \rightarrow 321.2$ ). The retention times of digoxin (and digoxin-d3) and pravastatin (and pravastatin-d3) were approximately 3.3 and 3.0 minutes, respectively. The total run time for an LC-MS/MS analysis was 7 minutes. Six-point calibration curves for digoxin and pravastatin in cell lysate samples (0.3-60 pmol/well [1-200 nM]) were constructed on the basis of the peak area ratios of analytes to the respective internal standard. Four-point quality control samples $(0.3,1,7.5$, and $50 \mathrm{pmol} / \mathrm{well}$ ) were used for method validation. The mean intra- and interday coefficients of variation were below $14.2 \%$ for digoxin and $13.7 \%$ for pravastatin, and the assay accuracy ranged from $85.9 \%$ to $106 \%$ for digoxin and $98.7 \%-114 \%$ for pravastatin.

Data Analysis. Data were analyzed by one-way analysis of variance (ANOVA) with Tukey's or Games-Howell multiple comparisons test or by non-parametric Kruskal-Wallis test using Statistical Package for Social Sciences (IBM SPSS 25). A $P$ value $<0.05$ was considered to indicate statistical significance. Data are presented as mean and S.D.

\section{Results}

Effects of Matrigel Overlay and DEX on Cell Morphology and Bile Canaliculi Formation. Matrigel overlay of confluent $\mathrm{HuH}-7$ cultures (Fig. 1A) resulted in a more homogenous cell population compared with standard cultures, one that exhibited two distinct cell morphologies with high multilayered cell clusters (Fig. 1A, Area 2; approx. $25 \%$ of the culture area) surrounded by flattened cells (Fig. 1A, Area 1; approx. $75 \%$ of the culture area). The CDF assay confirmed the morphologic difference between the standard and Matrigel-overlaid HuH-7 cultures (Fig. 1B). The clusters with cuboidal, hepatocyte-like morphology in the standard cultures displayed multiple bile canaliculilike structures visualized by CDF accumulation (Area 2; approx. 35\% of observed area) whereas the flat epithelium-like cells in Area 1 (approx. $65 \%$ of observed area) did not show any CDF accumulation. In contrast, Matrigel-overlaid cultures exhibited CDF accumulation in bile canaliculilike structures that were rather homogenously distributed (Fig. 1B). Moreover, the Matrigel-overlaid cultures had branched, tubular canaliculi that were shared by multiple cells (Supplemental Fig. 1). The canaliculilike tubules were significantly longer (Fig. 2A) and the mean number per

\section{B Standard Culture (Area 2)}

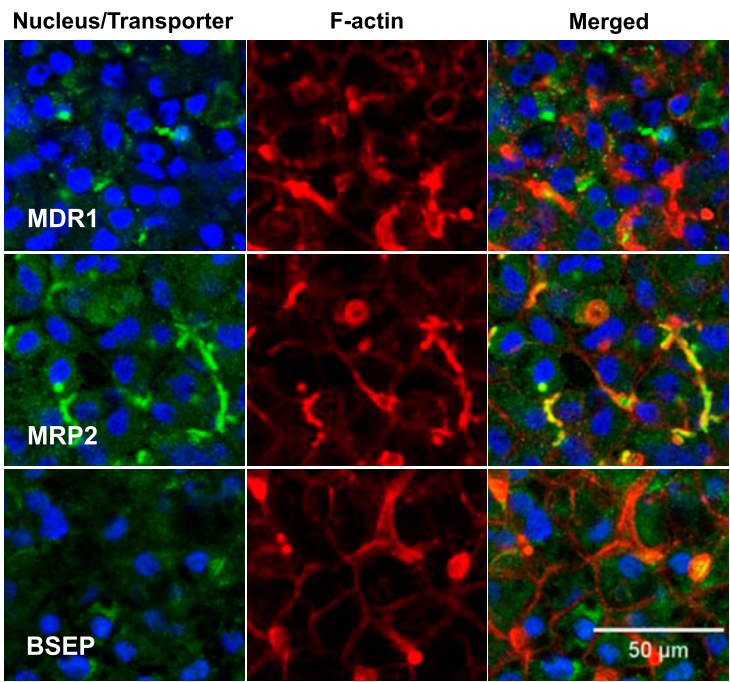

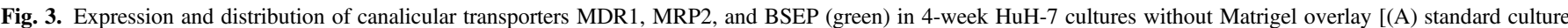
Area 1 and (B) Area 2]. Nuclei (blue) and F-actin (red) were labeled with DAPI and Alexa Fluor 594-phalloidin, respectively. 
cell tended to increase compared with those in Area 2 of standard cultures (Fig. 2B). Treatment with DEX increased the number and progressively elongated the F-actin-containing canalicular structures (Fig. 2).

Cellular Expression and Localization of Canalicular ABC Transporters. The effects of Matrigel overlay and DEX on expression of canalicular efflux transporters MDR1, MRP2, and BSEP were evaluated by immunostaining and immunoblotting (Figs. 3-5). In the standard culture, the surrounding flat cells (Area 1) did not express F-actin-containing canalicular structures or membrane-bound canalicular ABC transporters (Fig. 3A). Likewise, MDR1 and BSEP were not expressed in the F-actin-containing cell membrane of the hepatocytelike cells in the standard culture (Area 2), whereas MRP2 was

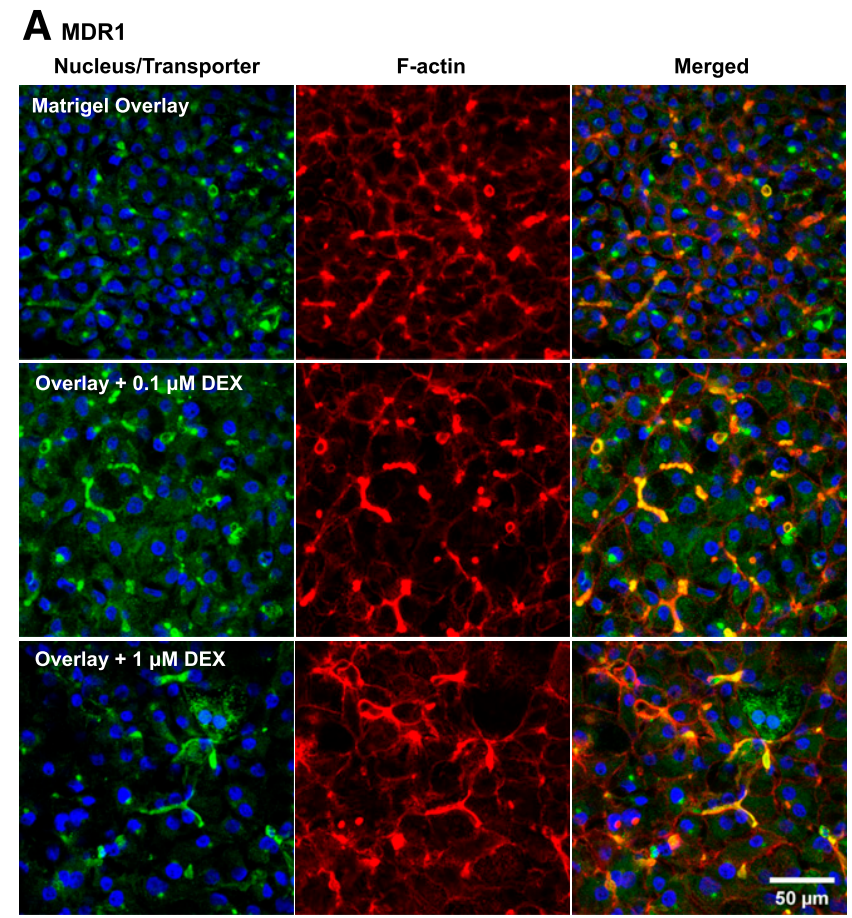

\section{BSEP}

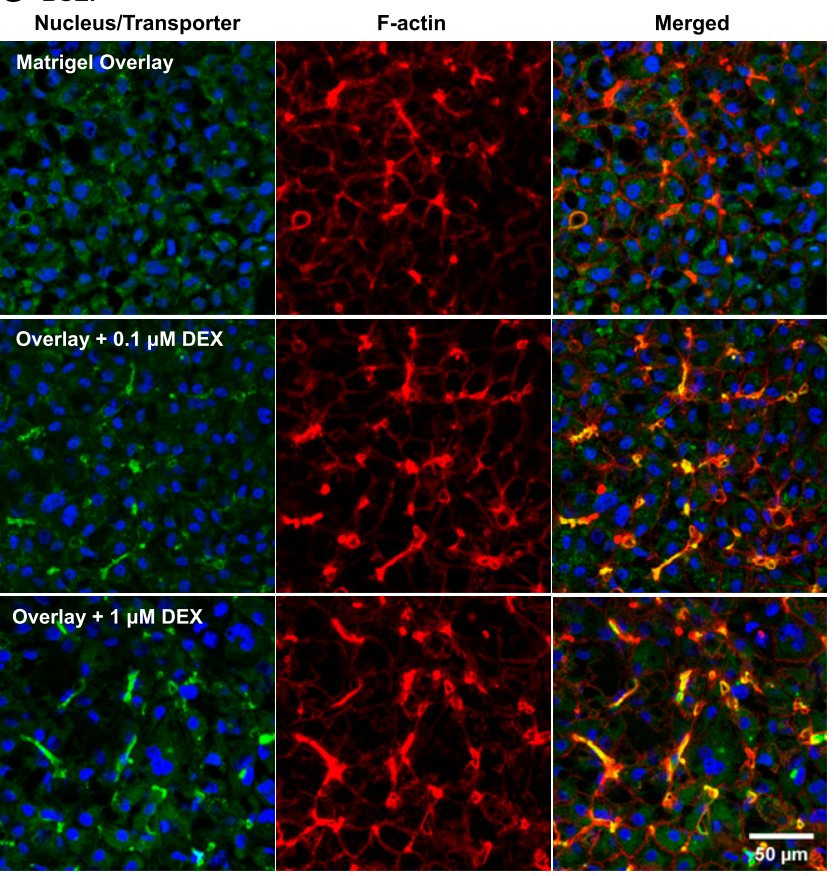

colocalized with F-actin-containing canalicular structures (Fig. 3B). These images served as respective negative controls confirming that the colocalization of MDR1, MRP2, and BSEP with F-actin in Fig. 4 is not a false signal. Matrigel overlay clearly increased expression of MDR1 on the canalicular membranes (Fig. 4A). MRP2 was expressed at the canalicular membranes of all 4-week confluent HuH-7 cultures, regardless of Matrigel or DEX addition (Figs. 3 and 4B). Interestingly, DEX supplementation induced the expression of BSEP both in Matrigeloverlaid (Figs. 4C and 5) and standard cultures (Supplemental Fig. 2). BSEP colocalized with F-actin, particularly in the cultures supplemented with DEX (Fig. 4C). However, DEX supplementation had minimal effects on the expression levels of MDR1 and MRP2 (Fig. 5).

\section{B MRP2}

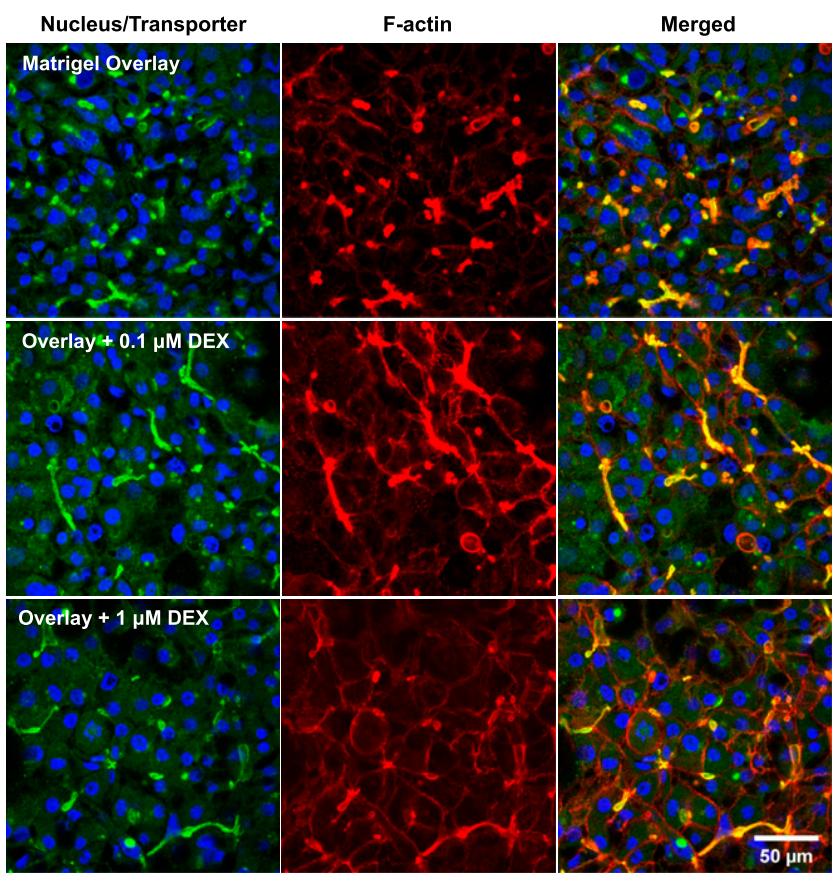

Fig. 4. Expression and distribution of canalicular transporters (A) MDR1, (B) MRP2, and (C) BSEP (green) in 4-week HuH-7 cultures with Matrigel overlay. HuH-7 cells were overlaid with Matrigel on culture day 22 and supplemented with $0,0.1$, or $1 \mu \mathrm{M}$ DEX from culture day 8 to 28 . Nuclei (blue) and F-actin (red) were labeled with DAPI and Alexa Fluor 594-phalloidin, respectively. 


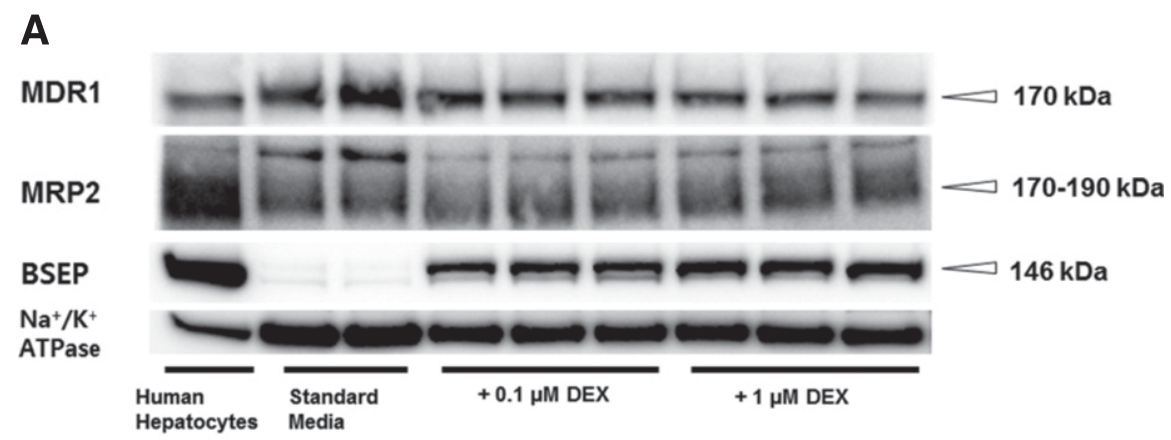

B MDR1
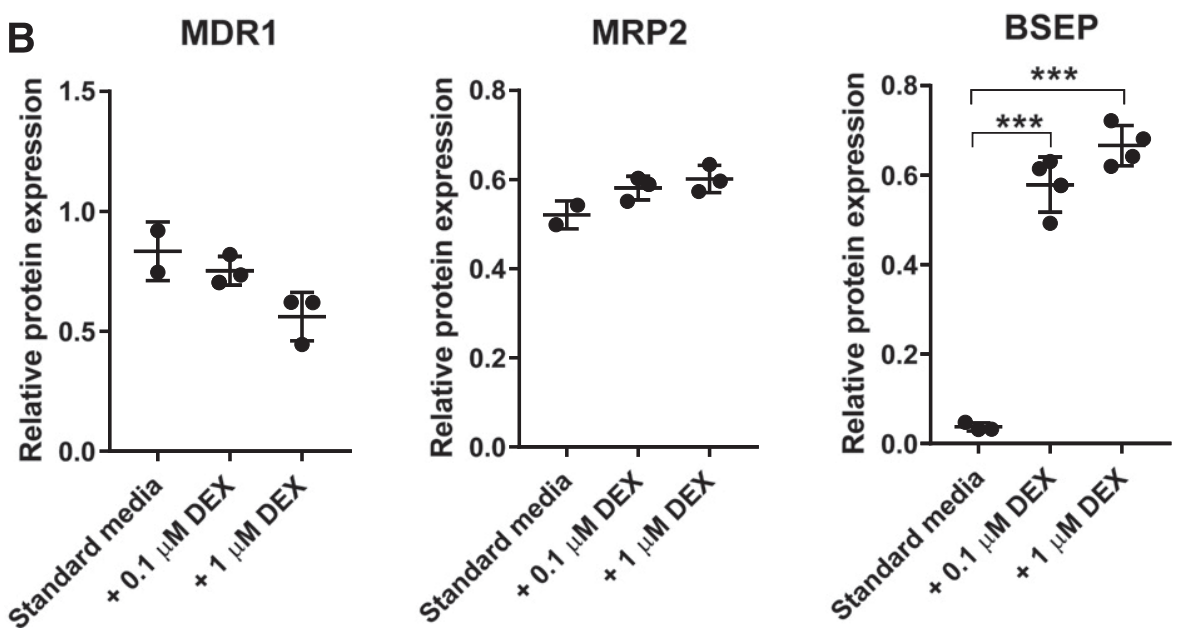

Fig. 5. Effect of DEX on the expression of MDR1, MRP2, and BSEP in 4-week HuH-7 cultures overlaid with Matrigel on culture day 22. (A) Representative immunoblots of MDR1, MRP2, BSEP, and $\mathrm{Na}^{+} / \mathrm{K}^{+}$ ATPase in 4-week Matrigel-overlaid $\mathrm{HuH}-7$ cultures and cryopreserved human hepatocytes (positive control). (B) Relative expression levels (mean \pm S.D.) of MDR1, MRP2, and BSEP in 4-week Matrigel-overlaid HuH-7 cultures supplemented with $0,0.1$, and $1 \mu \mathrm{M}$ DEX from culture day 8 to 28 ( $n=2-4$ each). $* * * P<$ 0.001 (one-way ANOVA with Tukey's test).
Biliary Excretion by Canalicular ABC Transporters. To evaluate the functionality of the canalicular $\mathrm{ABC}$ transporters, we first explored the applicability of B-CLEAR technology to HuH-7 cultures using the MRP2 substrate CDF as a canalicular marker. When the cells were exposed to $\mathrm{Ca}^{2+}$-containing standard HBSS, CDF remained within canalicular structures, whereas CDF accumulation was clearly lower after exposure of cells to $\mathrm{Ca}^{2+}$-free HBSS (Fig. 6) in both Matrigel-overlaid and standard cultures.

Somewhat surprisingly, standard HuH-7 cultures did not show a measurable BEI for any of the tested substrates (Figs. 7 and 8). The accumulation of digoxin, pravastatin, and TCA was similar or even higher in $\mathrm{Ca}^{2+}$-free HBSS than in $\mathrm{Ca}^{2+}$-containing HBSS in standard cultures. Biliary excretion of the MDR1 substrate digoxin was detected in Matrigel-overlaid cultures regardless of DEX supplementation (Fig. 7A). Matrigel-overlaid cultures supplemented with DEX exhibited measurable BEI for all three probe substrates. Biliary excretion of pravastatin and TCA was detected only when DEX was added to the maintenance medium (Figs. 7B and 8).

As a preliminary study, the optimal timing of the Matrigel overlay (1st, 2nd, and 3rd week after seeding $\mathrm{HuH}-7$ cells) was evaluated on the basis of the BEI of TCA that was excreted by BSEP into canaliculi. The maximal BEI was obtained when the cultures were overlaid with Matrigel at the 3 rd week after plating (i.e., 1 week before the B-CLEAR study) and supplemented with DEX (0.1 or $1 \mu \mathrm{M}$; data not shown). Matrigel-overlaid cultures also were compared with sandwich-cultured HuH-7 cells (collagen type I-coated surface with a Matrigel overlay); the BEI of TCA was not measurable in any sandwich-cultured HuH-7 cells with or without DEX supplementation (data not shown). The optimal preincubation time for each substrate in the B-CLEAR assay also was evaluated. A longer preincubation time ( 25 minutes) resulted in a higher and reproducible BEI for pravastatin and digoxin, whereas shorter (10 minutes) and longer (25 minutes) preincubation times resulted in comparable BEI values for TCA (data not shown). Two additional lots of Matrigel and the effects of phenol red in the maintenance medium were examined; the biliary excretion of TCA was consistently observed (BEI of $40 \%-50 \%$ ) in the modified culture conditions (Supplemental Fig. 3). $\nabla$ Standard Culture
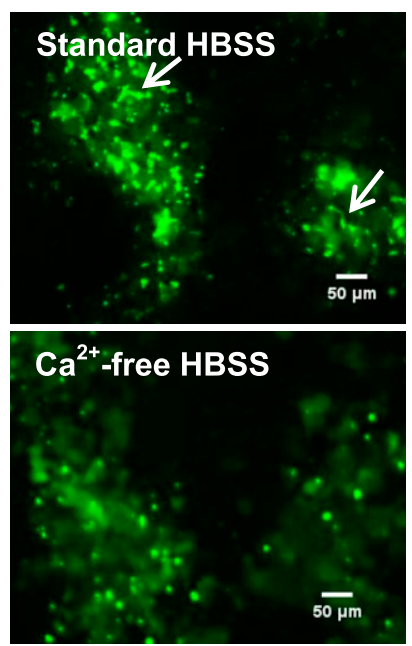

\section{$\nabla$ Matrigel Overlay}
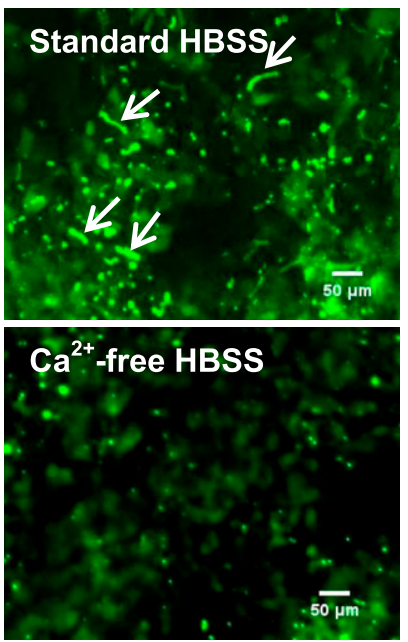

Fig. 6. Accumulation of $\mathrm{CDF}$ in 4-week HuH-7 cultures. $\mathrm{HuH}-7$ cells cultured with or without Matrigel overlay were preincubated with standard or $\mathrm{Ca}^{2+}$-free HBSS for 25 minutes followed by incubation for 20 minutes with CDFDA. Accumulation of $\mathrm{CDF}$, the fluorescent metabolite of CDFDA, within canaliculi-like structures is indicated by arrows. 

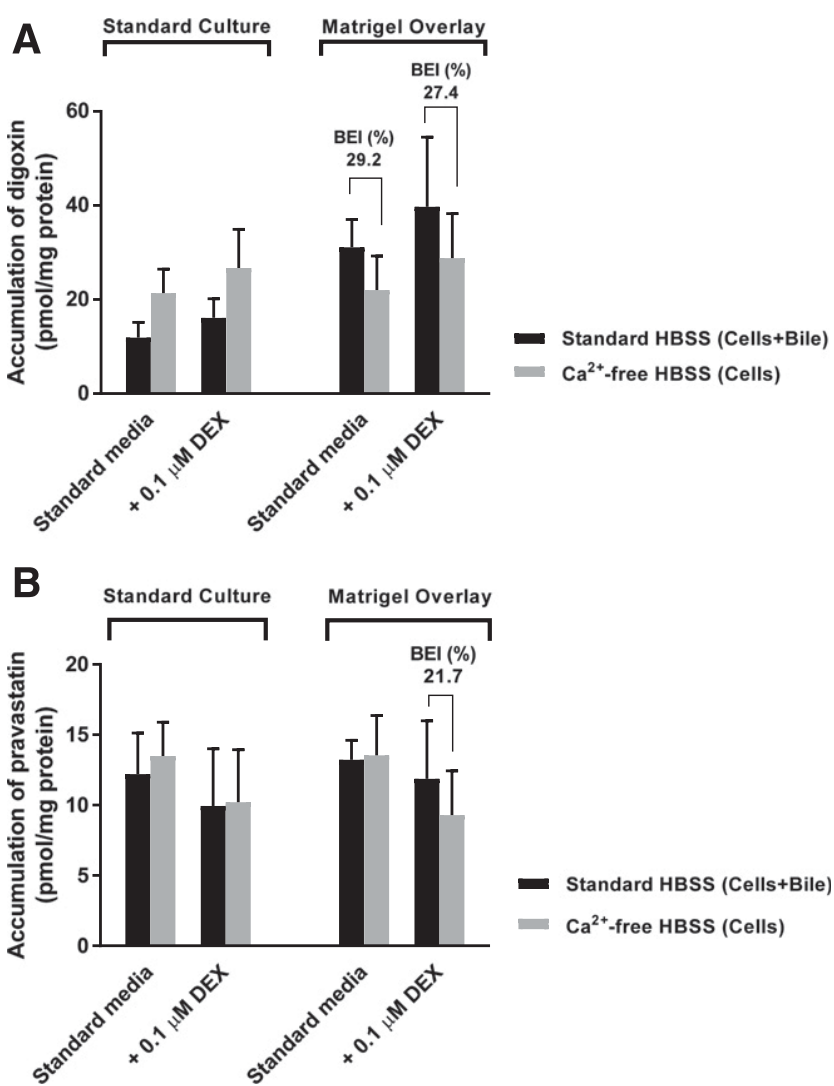

Fig. 7. Effect of Matrigel overlay and DEX on digoxin and pravastatin accumulation and canalicular excretion in 4-week HuH-7 cultures. Accumulation of (A) digoxin and (B) pravastatin was measured in cells + bile (preincubation with standard HBSS) and in cells (preincubation with $\mathrm{Ca}^{2+}$-free HBSS). Results represent mean \pm S.D. of two independent studies performed in triplicate. BEI (mean, \%) was calculated as described in Materials and Methods.

\section{Discussion}

In vitro models to predict hepatic drug disposition need to express sufficient levels of transporters that are correctly localized and functional. Although hepatic cell lines are more reproducible and costefficient to use than primary human hepatocytes, existing models do not completely replicate transporter expression and/or function in human hepatocytes (Olsavsky et al., 2007; Guo et al., 2011; Jouan et al., 2017). However, reports indicate that culturing $\mathrm{HuH}-7$ cells over several weeks at confluency gradually induces the protein and/or mRNA expression of multiple transporters (Sivertsson et al., 2010; Malinen et al., 2019). However, the expression of the major canalicular bile acid transporter BSEP was still very low after 4 weeks of culture, and MRP2 remained at a constant but lower level than in human hepatocytes (Malinen et al., 2019). The protein expression and function of MDR1 has not been evaluated at all in long-term HuH-7 cultures (Sivertsson et al., 2010; Malinen et al., 2019). The present study investigated whether extracellular matrix overlay (Matrigel) and glucocorticoid treatment (DEX), two frequent components of primary human hepatocyte cultures, could enhance the expression and function of the major canalicular $\mathrm{ABC}$ transporters MDR1, MRP2, and BSEP in confluent HuH-7 cultures. Overall, Matrigel overlay and DEX treatment restored the localization and function of MDR1 and BSEP, suggesting a robust maturation toward a hepatic phenotype.

Standard HuH-7 cultures appeared to differentiate into two distinct cell phenotypes, one with flat epithelium-like cells without canalicular structures and another with cuboidal hepatocyte-like cells with tubular canaliculi-like structures, as previously reported (Malinen et al., 2019).

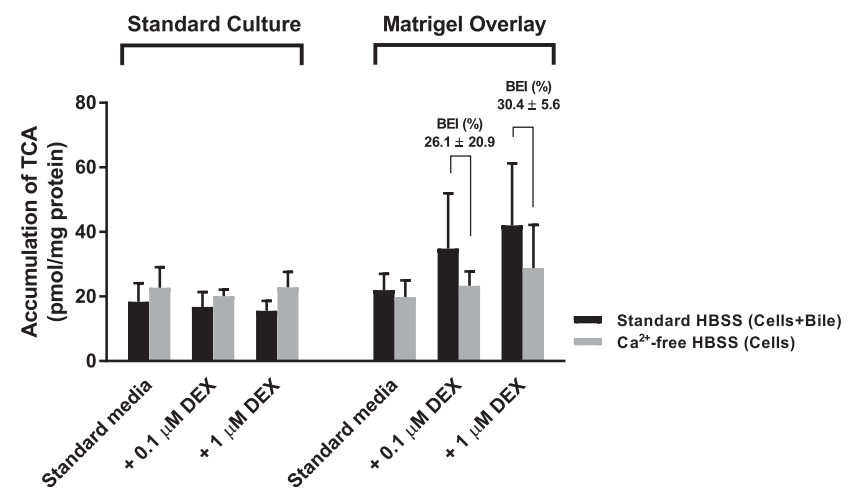

Fig. 8. Effect of Matrigel overlay and DEX on TCA accumulation and canalicular excretion in 4-week HuH-7 cultures. Accumulation of $\left[{ }^{3} \mathrm{H}\right]-\mathrm{TCA}$ in the cells + bile (preincubation with standard HBSS) and in cells (preincubation with $\mathrm{Ca}^{2+}$-free HBSS). Results represent mean \pm S.D. of three independent studies performed in triplicate. BEI (mean \pm S.D., \%) was calculated as described in Materials and Methods.

The appearance of two cell morphologies resembles the differentiation of the HepaRG cell line (Gripon et al., 2002; Hoekstra et al., 2011). The identity of bile canaliculi within the hepatocyte-like cell population was confirmed by distribution of F-actin, colocalization of MRP2 with F-actin, and accumulation of CDF, a fluorescent MRP2 substrate, within the canaliculi. Interestingly, Matrigel overlay resulted in a much higher proportion of hepatocyte-like cells (approx. 90\% of the culture area) and a notable increase in the homogeneity of the cell population compared with standard HuH-7 culture conditions where approx. $25 \%-35 \%$ of the culture area represented hepatocyte-like cells. HuH-7 cell spheroids embedded in a three-dimensional extracellular matrix using Matrigel also adopt a polarized phenotype (Molina-Jimenez et al., 2012). Likewise, HepaRG cells present a more hepatocyte-like phenotype when the cultures are overlaid with Matrigel or when the cells are cultured within a three-dimensional extracellular matrix (Malinen et al., 2014; Jackson et al., 2016).

Another advantage of the Matrigel overlay was that, on the basis of the CDF accumulation and F-actin staining, the canalicular structures appeared more extended than in the standard HuH-7 cell cultures. Spherical structures, shared by a few adjacent cells, were dominant in the standard cultures, whereas branched and tubular canaliculi connecting several cells were more abundant with the Matrigel overlay cultures. In addition, the proper canalicular expression, localization, and function of MDR1 were restored only in Matrigel-overlaid cultures.

DEX treatment seemed to extend the canalicular structures further, as shown by F-actin staining. Importantly, DEX induced the expression of BSEP protein in both standard and Matrigel-overlaid HuH-7 cultures. This is a remarkable finding, because hepatoma cell lines, unlike primary human hepatocytes, usually express BSEP at very low or unmeasurable levels (Guo et al., 2011; Mörk et al., 2012; Sison-Young et al., 2015; Wiśniewski et al., 2016). DEX increased expression of BSEP mRNA in HepG2 cells (Rosales et al., 2013), but there is no information on the protein level or functionality of BSEP in these cells.

It should be recognized that DEX is commonly used as a hormonal supplement in primary hepatocyte cultures at nanomolar concentrations $(25-100 \mathrm{nM})$ to maintain many hepatocyte-specific functions (Fraczek et al., 2013). In the present study, we applied the same $(0.1 \mu \mathrm{M})$ and 10 -fold higher concentrations $(1 \mu \mathrm{M})$ of DEX. Both concentrations promoted the formation of bile canaliculi and increased expression and function of BSEP. The molecular mechanism(s) by which DEX modulates the expression of BSEP in $\mathrm{HuH}-7$ cells remains to be determined; however, glucocorticoid receptor-mediated regulation of BSEP has been suggested in rat hepatocytes (Fardel et al., 2001). DEX 
TABLE 1

Summary of biliary excretion index (BEI), apparent in vitro uptake clearance $\left(\mathrm{CL}_{\text {uptake,app }}\right)$ and biliary clearance $\left(\mathrm{CL}_{\text {biliary,app }}\right)$ values of digoxin, pravastatin, and $\mathrm{TCA}$ in various hepatic cell models

\begin{tabular}{|c|c|c|c|}
\hline \multirow{2}{*}{ Substrates/Parameters } & \multicolumn{3}{|c|}{ In Vitro Hepatic Models } \\
\hline & $\mathrm{HuH}-7$ & Sandwich-Cultured Human Hepatocytes ${ }^{a}$ & HepaRG $^{a}$ \\
\hline \multicolumn{4}{|l|}{ Digoxin } \\
\hline BEI $(\%)$ & $27-29$ & $7-63^{b-d}$ & \\
\hline $\mathrm{CL}_{\text {uptake anp }}(\mu \mathrm{l} / \mathrm{min}$ per milligram protein $)$ & $1.0-1.3$ & $0.69-2.8^{b, d}$ & \\
\hline $\mathrm{CL}_{\text {biliary,app }}(\mu \mathrm{l} / \mathrm{min}$ per milligram protein) & $0.3-0.36$ & $0.18-2.4^{b-d}$ & \\
\hline \multicolumn{4}{|l|}{ Pravastatin } \\
\hline BEI $(\%)$ & 22 & $18-3^{c, e}$ & \\
\hline $\mathrm{CL}_{\text {uptake,app }}(\mu \mathrm{l} / \mathrm{min}$ per milligram protein $)$ & 0.4 & $1^{e}$ & \\
\hline $\mathrm{CL}_{\text {biliary,app }}(\mu \mathrm{l} / \mathrm{min}$ per milligram protein) & 0.086 & $0.25-0.55^{c, e}$ & \\
\hline \multicolumn{4}{|l|}{ TCA } \\
\hline BEI $(\%)$ & $26-50$ & $30-75^{b, d-f}$ & $27-39^{g-i}$ \\
\hline $\mathrm{CL}_{\text {uptake,app }}(\mu \mathrm{l} / \mathrm{min}$ per milligram protein $)$ & $1.2-2.1$ & $2.7-20^{b, d-f}$ & $2.7-13.8^{g, h}$ \\
\hline $\mathrm{CL}_{\text {biliary,app }}(\mu \mathrm{l} / \mathrm{min}$ per milligram protein) & $0.5-0.7$ & $0.8-25^{b, d-f}$ & $1-4^{g, h}$ \\
\hline
\end{tabular}

${ }^{a}$ The values were adopted or calculated from the following references:

${ }^{b} \mathrm{Bi}$ et al. (2006).

${ }^{c}$ Kimoto et al. (2017).

${ }^{d}$ Swift et al. (2009)

${ }^{e}$ Abe et al. (2009)

${ }^{f} \mathrm{Ni}$ et al. (2016).

${ }^{g}$ Le Vee et al. (2013).

${ }^{h}$ Susukida et al. (2016)

${ }^{i}$ Bachour-El Azzi et al. (2015).

treatment $(0.1$ or $1 \mu \mathrm{M})$ appeared to have minimal effects on the protein expression of MDR1 and MRP2, in agreement with a previous study performed in primary human hepatocytes with 2-50 $\mu \mathrm{M}$ DEX (Nishimura et al., 2006). Interestingly, 0.1 $\mu \mathrm{M}$ DEX treatment has been shown to activate a glucocorticoid-responsive element within the human MRP2 promoter (Qadri et al., 2009).

The suitability of B-CLEAR technology to quantify the BEI in the HuH-7 cultures was evaluated here for the first time. The decreased amount of CDF retained within canaliculi-like structures in cultures treated with $\mathrm{Ca}^{2+}$-free buffer compared with cultures treated with standard $\left(\mathrm{Ca}^{2+}\right.$-containing $)$ buffer resembled the findings in primary hepatocytes (Liu et al., 1999; Pfeifer et al., 2013) and suggested that the BEI may be estimated in HuH-7 cultures using B-CLEAR. Although accumulation of the MRP2 substrate CDF was detected in both standard and overlaid $\mathrm{HuH}-7$ cultures, BEI values were below the detection limit in the standard cultures for all substrates tested (digoxin, pravastatin, and TCA). This can be explained by the presence of two distinct cell populations in the standard cultures, of which the abundant epithelial-like flat cells lack canalicular structures and the proper expression and localization of MDR1, MRP2, and BSEP. Owing to their large surface area but minimal canaliculi, the epithelial-like cells would be able to take up the probe substrates (Malinen et al., 2019) but unable to excrete them efficiently, resulting in negligible BEI values.

In standard culture conditions without Matrigel overlay, preincubation with $\mathrm{Ca}^{2+}$-free HBSS resulted in higher accumulation of digoxin compared with standard HBSS. A similar trend also was observed with TCA. The flat epithelium-like cells in the standard culture expressed basolateral SLC-family transporters, and cellular uptake of TCA was increased in the low sodium buffer (Malinen et al., 2019). $\mathrm{Ca}^{2+}$-free conditions may alter the function of these basolateral transporters through the disturbance of cellular sodium ion homeostasis (Bouscarel et al., 1996; Carini et al., 1997).

The Matrigel-overlaid HuH-7 cultures correctly localized MDR1 to the canalicular domain and excretion of the MDR1 substrate digoxin into the canalicular compartment was measurable (BEI of 27\%-29\%). The canalicular excretion of pravastatin (BEI approx. 22\%) could be measured only in Matrigel-overlaid and DEX-supplemented cultures even though MRP2 was colocalized with F-actin-rich bile canaliculi in all HuH-7 cultures. Additional DEX supplementation may have enabled a detectable BEI of pravastatin in Matrigel-overlaid HuH-7 cultures owing to the favorable effects of DEX on bile canaliculi formation, but not resulting from induction of MRP2 expression by DEX, as mentioned above. The canalicular excretion of TCA (BEI of $26 \%-50 \%$ ) could be measured only when the Matrigel-overlaid cultures were supplemented with DEX, which is consistent with DEX induction of BSEP expression and proper BSEP localization by the Matrigel overlay. Overall, the observed BEI values for digoxin and pravastatin in modified $\mathrm{HuH}-7$ cultures were slightly lower than those published for sandwich-cultured human hepatocytes (Table 1). The observed BEI values for TCA were comparable to that in differentiated HepaRG cells but slightly lower than the reported values for sandwich-cultured human hepatocytes (Table 1). The apparent in vitro uptake clearance $\left(\mathrm{CL}_{\text {uptake,app }}\right)$ and biliary clearance $\left(\mathrm{CL}_{\text {biliary,app }}\right)$ values of digoxin, pravastatin, and TCA in the HuH-7 cultures were lower than those in sandwich-cultured human hepatocytes (Table 1). This may be caused by slower net uptake of substrates, because Huh7 cells exhibit lower expression of basolateral OATPs and higher expression of basolateral MRP4 and OST $\alpha / \beta$ compared with human hepatocytes (Malinen et al., 2019).

In conclusion, these results illustrate that Matrigel overlay and DEX treatment enhanced the hepatic maturation of confluent 4-week HuH-7 cultures. The modified conditions increased the proportion of hepatocyte-like cells, strongly augmented the canalicular structures between the cells, and restored the localization and function of key canalicular ABC transporters. Our findings suggest that the modified HuH-7 cultures have the potential to function as a surrogate for primary human hepatocytes in MDR1-, MRP2-, and BSEP-mediated biliary excretion studies. However, the effect of Matrigel overlay and DEX supplementation on the expression and function of basolateral transporters and DMEs remains to be investigated.

\section{Acknowledgments}

The authors thank Dr. Tatsuya Sueyoshi, National Institute of Environmental Health Sciences (NIEHS), Research Triangle Park, NC, for confirmation of the identity of the HuH-7 cell line. 


\section{Authorship Contributions}

Participated in research design: Kang, Malinen, Brouwer.

Conducted experiments: Kang, Malinen, Saran.

Performed data analysis: Kang, Malinen, Honkakoski, Brouwer.

Wrote or contributed to the writing of the manuscript: Kang, Malinen, Honkakoski, Brouwer.

\section{References}

Abe K, Bridges AS, and Brouwer KLR (2009) Use of sandwich-cultured human hepatocytes to predict biliary clearance of angiotensin II receptor blockers and HMG-CoA reductase inhibitors. Drug Metab Dispos 37:447-452.

Bachour-El Azzi P, Sharanek A, Burban A, Li R, Guével RL, Abdel-Razzak Z, Stieger B, GuguenGuillouzo C, and Guillouzo A (2015) Comparative localization and functional activity of the main hepatobiliary transporters in HepaRG cells and primary human hepatocytes. Toxicol Sci 145: $157-168$

Bi YA, Kazolias D, and Duignan DB (2006) Use of cryopreserved human hepatocytes in sandwich culture to measure hepatobiliary transport. Drug Metab Dispos 34:1658-1665.

Bouscarel B, Reza S, Dougherty LA, Fromm H, and Nussbaum R (1996) Regulation of taurocholate and ursodeoxycholate uptake in hamster hepatocytes by $\mathrm{Ca}(2+)$-mobilizing agents. $\mathrm{Am}$ J Physiol 271:G1084-G1095.

Carini R, de Cesaris MG, Bellomo G, and Albano E (1997) Role of $\mathrm{Na}+/ \mathrm{Ca} 2+$ exchanger in preventing $\mathrm{Na}+$ overload and hepatocyte injury: opposite effects of extracellular and intracellular $\mathrm{Ca} 2+$ chelation. Biochem Biophys Res Commun 232:107-110.

Donato MT, Jover R, and Gómez-Lechón MJ (2013) Hepatic cell lines for drug hepatotoxicity testing: limitations and strategies to upgrade their metabolic competence by gene engineering. Curr Drug Metab 14:946-968.

Fardel O, Payen L, Courtois A, Vernhet L, and Lecureur V (2001) Regulation of biliary drug efflux pump expression by hormones and xenobiotics. Toxicology 167:37-46.

Fraczek J, Bolleyn J, Vanhaecke T, Rogiers V, and Vinken M (2013) Primary hepatocyte cultures for pharmaco-toxicological studies: at the busy crossroad of various anti-dedifferentiation strategies. Arch Toxicol 87:577-610.

Gerets HH, Tilmant K, Gerin B, Chanteux H, Depelchin BO, Dhalluin S, and Atienzar FA (2012) Characterization of primary human hepatocytes, HepG2 cells, and HepaRG cells at the mRNA level and CYP activity in response to inducers and their predictivity for the detection of human hepatotoxins. Cell Biol Toxicol 28:69-87.

Gripon P, Rumin S, Urban S, Le Seyec J, Glaise D, Cannie I, Guyomard C, Lucas J, Trepo C, and Guguen-Guillouzo C (2002) Infection of a human hepatoma cell line by hepatitis B virus. Proc Natl Acad Sci USA 99:15655-15660.

Guo L, Dial S, Shi L, Branham W, Liu J, Fang JL, Green B, Deng H, Kaput J, and Ning B (2011) Similarities and differences in the expression of drug-metabolizing enzymes between human hepatic cell lines and primary human hepatocytes. Drug Metab Dispos 39:528-538.

Hoekstra R, Nibourg GA, van der Hoeven TV, Ackermans MT, Hakvoort TB, van Gulik TM, Lamers WH, Elferink RP, and Chamuleau RA (2011) The HepaRG cell line is suitable for bioartificial liver application. Int J Biochem Cell Biol 43:1483-1489.

Hoffmaster KA, Turncliff RZ, LeCluyse EL, Kim RB, Meier PJ, and Brouwer KLR (2004) $\mathrm{P}$-glycoprotein expression, localization, and function in sandwich-cultured primary rat and human hepatocytes: relevance to the hepatobiliary disposition of a model opioid peptide. Pharm Res 21:1294-1302.

Jackson JP, Li L, Chamberlain ED, Wang H, and Ferguson SS (2016) Contextualizing hepatocyte functionality of cryopreserved HepaRG cell cultures. Drug Metab Dispos 44:1463-1479.

Jouan E, Le Vée M, Denizot C, Parmentier Y, and Fardel O (2017) Drug transporter expression and activity in human hepatoma HuH-7 cells. Pharmaceutics 9:3. DOI: 10.3390/ pharmaceutics9010003.

Kimoto E, Bi YA, Kosa RE, Tremaine LM, and Varma MVS (2017) Hepatobiliary clearance prediction: species scaling from monkey, dog, and rat, and in vitro-in vivo extrapolation of sandwich-cultured human hepatocytes using 17 drugs. J Pharm Sci 106:2795-2804.

Kubitz R, Warskulat U, Schmitt M, and Häussinger D (1999) Dexamethasone- and osmolaritydependent expression of the multidrug-resistance protein 2 in cultured rat hepatocytes. Biochem J 340:585-591.

LeCluyse EL, Audus KL, and Hochman JH (1994) Formation of extensive canalicular networks by rat hepatocytes cultured in collagen-sandwich configuration. Am J Physiol 266 C1764-C1774.

Le Vee M, Noel G, Jouan E, Stieger B, and Fardel O (2013) Polarized expression of drug transporters in differentiated human hepatoma HepaRG cells. Toxicol In Vitro 27:1979-1986.

Liu X, LeCluyse EL, Brouwer KR, Gan LS, Lemasters JJ, Stieger B, Meier PJ, and Brouwer KLR (1999) Biliary excretion in primary rat hepatocytes cultured in a collagen-sandwich configuration. Am J Physiol 277:G12-G21.

Malinen MM, Ito K, Kang HE, Honkakoski P, and Brouwer KLR (2019) Protein expression and function of organic anion transporters in short-term and long-term cultures of Huh7 human hepatoma cells. Eur J Pharm Sci 130:186-195.

Malinen MM, Kanninen LK, Corlu A, Isoniemi HM, Lou YR, Yliperttula ML, and Urtti AO (2014) Differentiation of liver progenitor cell line to functional organotypic cultures in 3D nanofibrillar cellulose and hyaluronan-gelatin hydrogels. Biomaterials 35:5110-5121.
Matsushima S, Maeda K, Kondo C, Hirano M, Sasaki M, Suzuki H, and Sugiyama Y (2005) Identification of the hepatic efflux transporters of organic anions using double-transfected Madin-Darby canine kidney II cells expressing human organic anion-transporting polypeptide 1B1 (OATP1B1)/multidrug resistance-associated protein 2, OATP1B1/multidrug resistance 1 , and OATP1B1/breast cancer resistance protein. J Pharmacol Exp Ther 314:1059-1067.

Molina-Jimenez F, Benedicto I, Dao Thi VL, Gondar V, Lavillette D, Marin JJ, Briz O, MorenoOtero R, Aldabe R, Baumert TF, et al. (2012) Matrigel-embedded 3D culture of Huh-7 cells as a hepatocyte-like polarized system to study hepatitis C virus cycle. Virology 425:31-39.

Mörk LM, Isaksson B, Boran N, Ericzon BG, Strom S, Fischler B, and Ellis E (2012) Comparison of culture media for bile acid transport studies in primary human hepatocytes. J Clin Exp Hepatol 2:315-322.

Nakabayashi H, Taketa K, Miyano K, Yamane T, and Sato J (1982) Growth of human hepatoma cells lines with differentiated functions in chemically defined medium. Cancer Res 42:3858-3863.

Ni X, Gao Y, Wu Z, Ma L, Chen C, Wang L, Lin Y, Hui L, and Pan G (2016) Functional human induced hepatocytes (hiHeps) with bile acid synthesis and transport capacities: a novel in vitro cholestatic model. Sci Rep 6:38694.

Nishimura M, Koeda A, Suzuki E, Kawano Y, Nakayama M, Satoh T, Narimatsu S, and Naito S (2006) Regulation of mRNA expression of MDR1, MRP1, MRP2 and MRP3 by prototypical microsomal enzyme inducers in primary cultures of human and rat hepatocytes. Drug Metab Pharmacokinet 21:297-307.

Olsavsky KM, Page JL, Johnson MC, Zarbl H, Strom SC, and Omiecinski CJ (2007) Gene expression profiling and differentiation assessment in primary human hepatocyte cultures, established hepatoma cell lines, and human liver tissues. Toxicol Appl Pharmacol 222:42-56.

Pfeifer ND, Yang K, and Brouwer KLR (2013) Hepatic basolateral efflux contributes significantly to rosuvastatin disposition I: characterization of basolateral versus biliary clearance using a novel protocol in sandwich-cultured hepatocytes. J Pharmacol Exp Ther 347:727-736.

Qadri I, Hu LJ, Iwahashi M, Al-Zuabi S, Quattrochi LC, and Simon FR (2009) Interaction of hepatocyte nuclear factors in transcriptional regulation of tissue specific hormonal expression of human multidrug resistance-associated protein 2 (abcc2). Toxicol Appl Pharmacol 234:281-292.

Rosales R, Romero MR, Vaquero J, Monte MJ, Requena P, Martinez-Augustin O, Sanchez de Medina F, and Marin JJ (2013) FXR-dependent and -independent interaction of glucocorticoids with the regulatory pathways involved in the control of bile acid handling by the liver. Biochem Pharmacol 85:829-838.

Shi J, Wang X, Lyu L, Jiang H, and Zhu HJ (2018) Comparison of protein expression between human livers and the hepatic cell lines HepG2, Hep3B, and Huh7 using SWATH and MRM-HR proteomics: focusing on drug-metabolizing enzymes. Drug Metab Pharmacokinet 33:133-140. Sison-Young RL, Mitsa D, Jenkins RE, Mottram D, Alexandre E, Richert L, Aerts H, Weaver RJ, Jones RP, Johann E, et al. (2015) Comparative proteomic characterization of 4 human liverderived single cell culture models reveals significant variation in the capacity for drug disposition, bioactivation, and detoxication. Toxicol Sci 147:412-424.

Sivertsson L, Ek M, Darnell M, Edebert I, Ingelman-Sundberg M, and Neve EP (2010) CYP3A4 catalytic activity is induced in confluent Huh7 hepatoma cells. Drug Metab Dispos 38:995-1002.

Susukida T, Sekine S, Nozaki M, Tokizono M, Oizumi K, Horie T, and Ito K (2016) Establishment of a drug-induced, bile acid-dependent hepatotoxicity model using HepaRG cells. J Pharm Sci 105: $1550-1560$.

Swift B, Pfeifer ND, and Brouwer KLR (2010) Sandwich-cultured hepatocytes: an in vitro model to evaluate hepatobiliary transporter-based drug interactions and hepatotoxicity. Drug Metab Rev 42:446-471.

Swift B, Tian X, and Brouwer KLR (2009) Integration of preclinical and clinical data with pharmacokinetic modeling and simulation to evaluate fexofenadine as a probe for hepatobiliary transport function. Pharm Res 26:1942-1951.

Tanaka K, Sato M, Tomita Y, and Ichihara A (1978) Biochemical studies on liver functions in primary cultured hepatocytes of adult rats. I. Hormonal effects on cell viability and protein synthesis. J Biochem 84:937-946.

Varandani PT, Darrow RM, Nafz MA, and Norris GL (1982) Binding, degradation, and bioactivity of insulin in primary cultures of rat hepatocytes. Am J Physiol 243:E132-E139.

Warskulat U, Kubitz R, Wettstein M, Stieger B, Meier PJ, and Häussinger D (1999) Regulation of bile salt export pump mRNA levels by dexamethasone and osmolarity in cultured rat hepatocytes. Biol Chem 380:1273-1279.

Wiśniewski JR, Vildhede A, Norén A, and Artursson P (2016) In-depth quantitative analysis and comparison of the human hepatocyte and hepatoma cell line HepG2 proteomes. J Proteomics 136:234-247.

Yang K, Pfeifer ND, Köck K, and Brouwer KLR (2015) Species differences in hepatobiliary disposition of taurocholic acid in human and rat sandwich-cultured hepatocytes: implications for drug-induced liver injury. J Pharmacol Exp Ther 353:415-423.

Zamek-Gliszczynski MJ, Xiong H, Patel NJ, Turncliff RZ, Pollack GM, and Brouwer KLR (2003) Pharmacokinetics of 5 (and 6)-carboxy-2', $7^{\prime}$-dichlorofluorescein and its diacetate promoiety in the liver. J Pharmacol Exp Ther 304:801-809.

Address correspondence to: Dr. Kim L.R. Brouwer, Division of Pharmacotherapy and Experimental Therapeutics, UNC Eshelman School of Pharmacy, University of North Carolina at Chapel Hill, CB\#7569, Chapel Hill, NC 27599-7569. E-mail: kbrouwer@unc.edu 